\title{
Hydrophilic Magnetofluorescent Nanobowls: Rapid Magnetic Response and Efficient
}

\section{Photoluminescence}

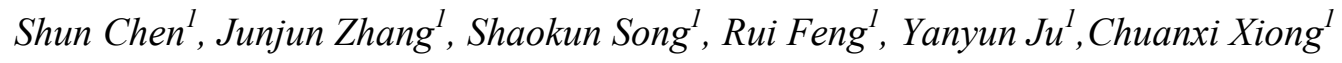
and Lijie Dong ${ }^{1,2 *}$

1 School of Materials Science and Engineering, Wuhan University of Technology, Luoshi Road 122, Wuhan 430070, P.R. China

2 Department of Materials Science and Engineering, Cornell University, Ithaca, New York 14850, United States

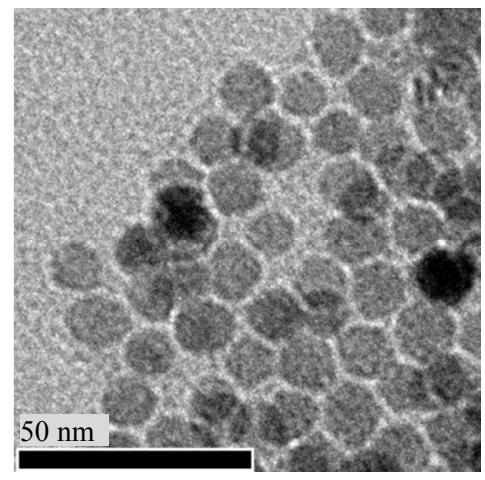

Figure S1. TEM image of monodisperse $\mathrm{Fe}_{3} \mathrm{O}_{4}$-PESA nanoparticles

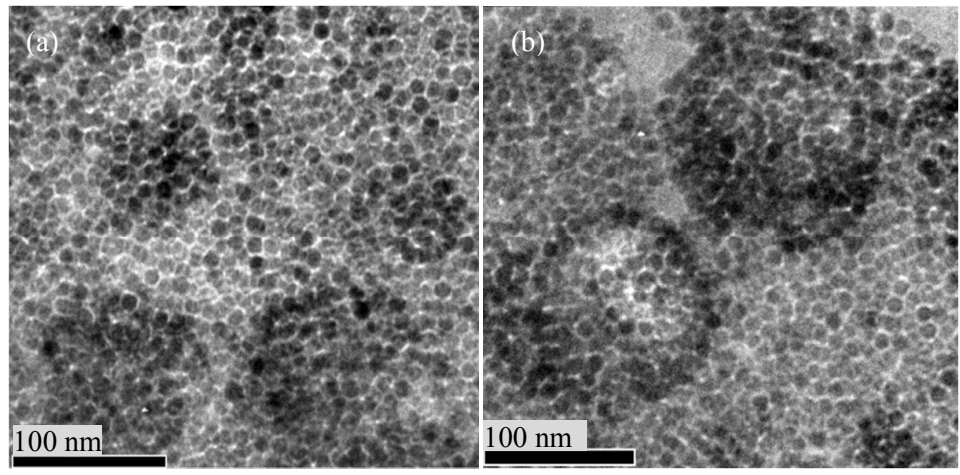




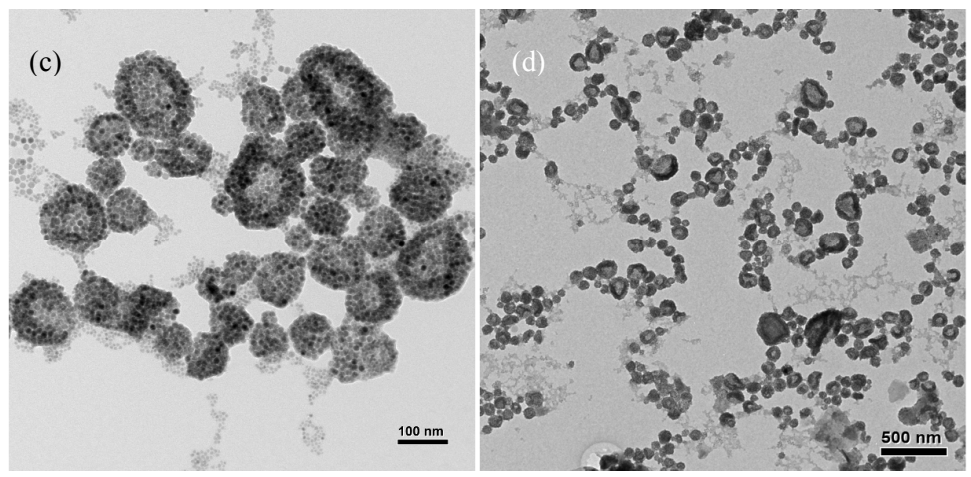

Figure S2. TEM images of $\mathrm{Fe}_{3} \mathrm{O}_{4}$-PESA superparticles during different stages. TEM image of $\mathrm{Fe}_{3} \mathrm{O}_{4}-\mathrm{PESA}$ superparticles: a) after ultrasonication; b) at the beginning of vacuum; c) and d) at the end of vacuum
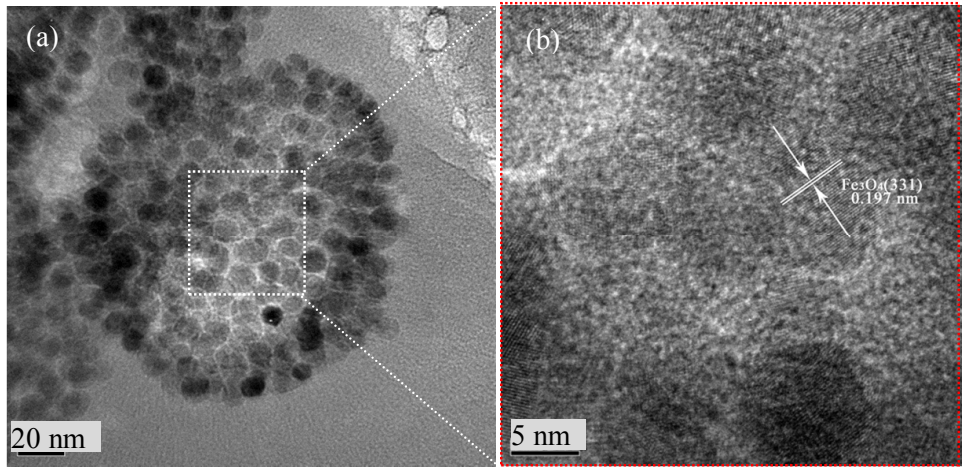

Figure S3. a) TEM image of single $\mathrm{Fe}_{3} \mathrm{O}_{4}$-PESA superparticle; b) HRTEM image of single $\mathrm{Fe}_{3} \mathrm{O}_{4}$-PESA superparticle

(a)

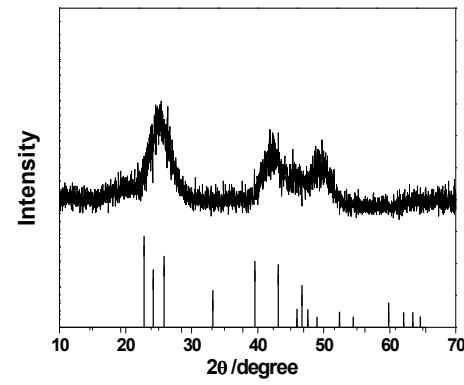

(c)

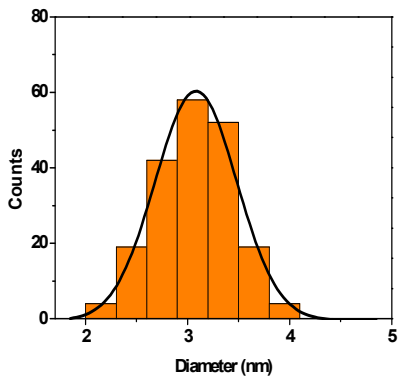

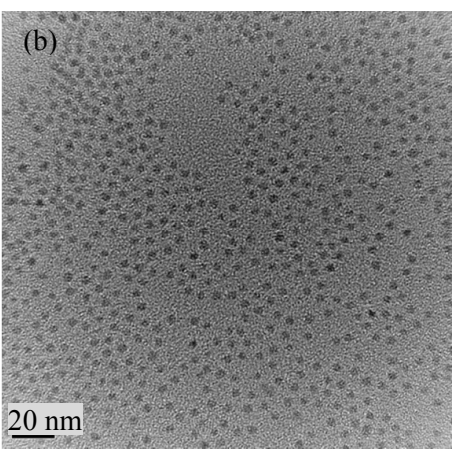

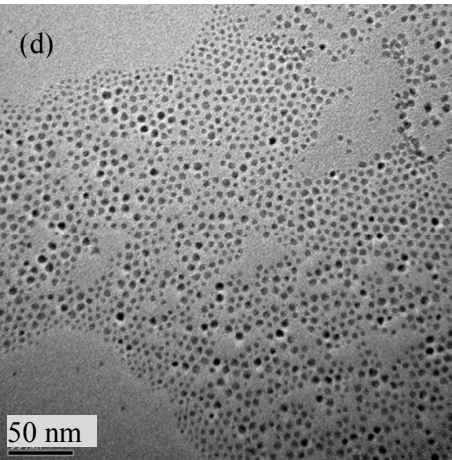



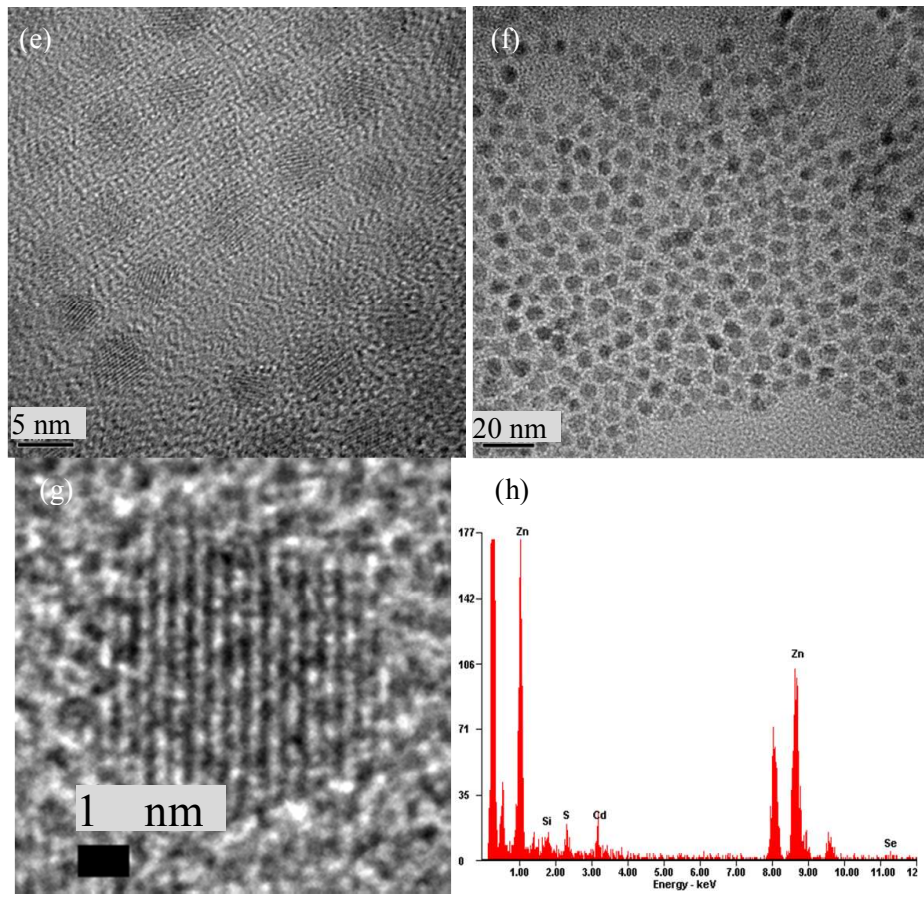

(h)

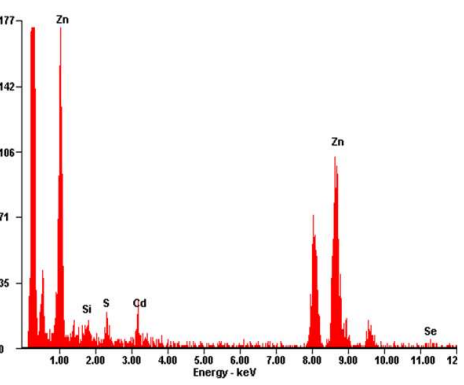

Figure S4. a) XRD patterns of CdSe nanocrystals; b)TEM image of CdSe nanocrystals; c) Size analysis of CdSe nanocrystal; d) TEM image of CdSe/CdS nanocrystals; e) HRTEM image of CdSe/CdS nanocrystals; f) TEM image of CdSe/CdS/ZnS nanocrystals; g) HRTEM image of CdSe/CdS/ZnS nanocrystal; h)EDX spectroscopy of $\mathrm{CdSe} / \mathrm{CdS} / \mathrm{ZnS}$ nanocrystals.
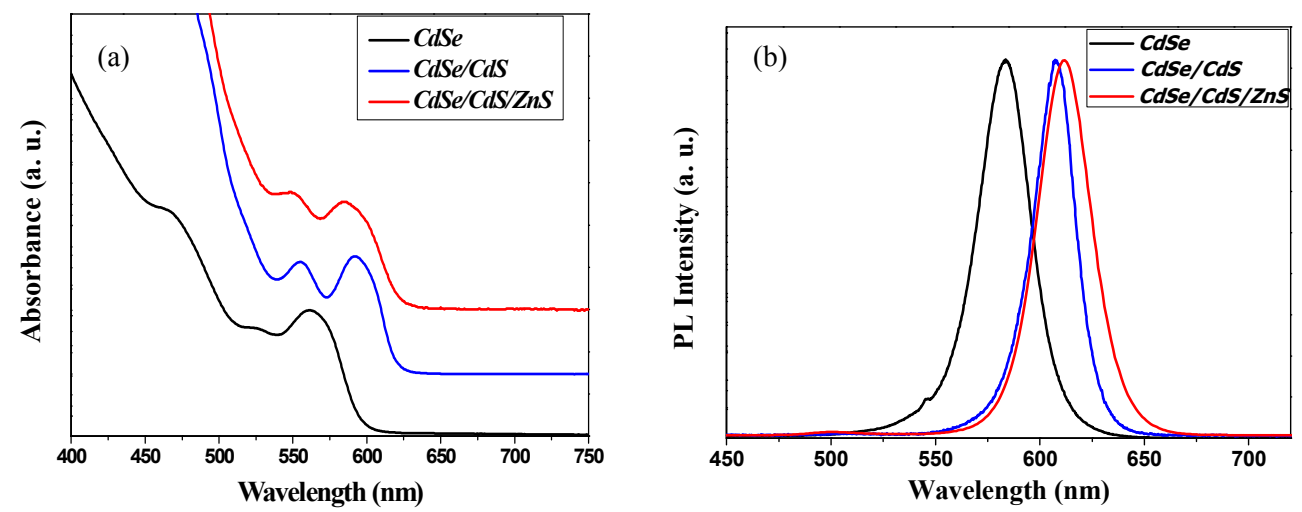

Figure S5. a) The UV-vis absorption of $\mathrm{CdSe}, \mathrm{CdSe} / \mathrm{CdS}, \mathrm{CdSe} / \mathrm{CdS} / \mathrm{ZnS}$; b)the photoluminescence spectrum of $\mathrm{CdSe}, \mathrm{CdSe} / \mathrm{CdS}, \mathrm{CdSe} / \mathrm{CdS} / \mathrm{ZnS}$ 